\title{
Binary Encoding
}

National Cancer Institute

\section{Source}

National Cancer Institute. Binary Encoding. NCI Thesaurus. Code C83478.

The representation of symbols in a source alphabet by strings of binary digits. 